\title{
Attitude in Appraisal Theory: A Comparative Analysis of English Versions of Changgan Xing
}

Tian Dong, Xiaolin Lin*

${ }^{1}$ Professor in School of Foreign Languages, North China Electric Power University, ${ }^{2}$ Graduate Student in School of Foreign Languages, North China Electric Power University 689 Huadian Road, Baoding, Hebei, China

Corresponding Author: Xiaolin Lin, E-mail: 376604118@qq.com

\section{ARTICLE INFO}

Article history

Received: December 12, 2017

Accepted: January 18, 2018

Published: January 31, 2018

Volume: 6 Issue: 1

Advance access: 2018

Conflicts of interest: None

Funding: None

\section{Key words:}

Poem translation,

Attitude system,

Distribution,

Realization

\begin{abstract}
This study intends to explore the distribution of appraisal resources in the English versions of Li Bai's poem Changgan Xing. It aims to make a comparative analysis and find out the similarities and differences of the translated poems based on J. R. Martin's Appraisal Theory. Two classical English versions of the Chinese poem, which were translated by Ezra Pound and Xu Yuanchong, have been chosen. The distribution of attitudinal resources in the two English versions has been analyzed under the attitude system from three aspects: affect, judgment and appreciation. The distribution of polarity and explicitness in the poems has been explored as well. The study has adopted quantitative and qualitative methods to conduct a comparative analysis of the attitudinal resources in the translated poems. Further, the reasons for the differences of attitudinal resources in the translated versions have been explored. Through revealing the similarities and differences of the attitudinal resources, this study shows the applicability of the Appraisal Theory in the comparative studies of Chinese-English poems.
\end{abstract}

\section{INTRODUCTION}

Li Bai is one of the greatest romantic poets of Tang Dynasty in China. He wrote more than 1000 poems throughout his life, which occupy an important position in the development of Chinese classical poetry. Therefore, the study of the English versions of Li Bai's poems has a great influence on the promotion of Chinese classical culture. His folk poetry Changgan Xing is a masterpiece in the history of poetry. This poem vividly describes how a woman misses her husband who had gone to do business for a long time and also describes the woman's psychological changes during different stages.

In the history, Changgan Xing had been translated by a number of Chinese and foreign scholars, including Ezra Pound, Amy Lowell, Xu Yuanchong, Wang Yushu and so on. Two translation versions stand out, which are translated by Ezra Pound and Xu Yuanchong. This paper will make a comparative analysis between two English versions. The first English version comes from Pound's masterpiece $\mathrm{Ca}$ thay, which first published in 1915 and contains 108 ancient Chinese poems. Li Bai's works accounted for up to eleven poems. It is praised by western critics as America's most beautiful poetry in $20^{\text {th }}$ century. The second English version is selected from Xu Yuanchong's Selected Poems of Li Bai, which includes more than one hundred poems of Li Bai and was first published in 1987. It is highly praised by western translators and attracts many scholars' attention. Numerous scholars have done researches mainly on Pound's version.

The study of Li Bai's poetry can be diversified, which can be combined with other theories such as the latest development of linguistic study to carry out more detailed researches. The application of Appraisal Theory to study the two English versions of Changgan Xing is such a kind of exploration. The Appraisal Theory was first advanced by J. R. Martin, which belongs to the study of ideational meaning in system functional linguistics. This study will be conducted under the attitude system in Appraisal Theory, which can be further divided into three aspects: affect, judgment and appreciation. The objective of this study is to make a comparative analysis of the two English versions of Changgan Xing based on the attitude system in the Appraisal Theory. To achieve this goal, quantitative and qualitative methods will be adopted to conduct the study. The study will reveal the similarities and differences between the distributions of attitudinal resources in the two English versions of Changgan Xing and the reasons for the differences will be further analyzed. The study will be helpful to prove that the Appraisal Theory can be applied to making a comparative study of the translation of Chinese poetry. 


\section{LITERATURE REVIEW}

\section{Studies of Appraisal Theory Abroad}

System functional linguistics (SFL) has focused on the lexico-grammatical study of the three metafunctions - ideational meaning, interpersonal meaning and textual meaning by taking clause as representation, exchange and message. The research covers a vast scope in great depth, but it ig ores the semantics of evaluation. James Robert Martin noted this blind spot in the early 1990s and proposed the Appraisal Theory on the basis of SFL. Martin first put forward the whole Appraisal Theory in his thesis Beyond Exchange: Appraisal Systems in English published in 2000, since then Appraisal Theory has been attracting worldwide attention. Later Martin and David Rose make a detailed description of the Appraisal system in their book Working with Discourse to construct a framework for the analysis of interpersonal meaning and other kinds of meaning. Martin and P.R.R. White also coworked the book The Language of Evaluation: Appraisal in English in 2005 and give a detailed explanation of the theory of appraisal in their book. White founded a discussion group of Appraisal Theory on website which attracts a number of scholars and graduates to participate in the relevant studies and activities. That greatly benefits the development of Appraisal Theory. Meanwhile, Text (or Text \& Talk), which is the specific Journal for Appraisal Theory, publishes the special issue for the application and development of Appraisal Theory. The International Conference on Evaluation and Text Types sponsored by the University of Augsburg was convened from July 22 to 23, 2005. Since then, studies on appraisal theory in text have been paid much more attention by scholars.

\section{Studies of Appraisal Theory at Home}

In china, a number of scholars also made contribution to the development of Appraisal Theory. Wang Zhenhua "tries to present some background knowledge of Appraisal System, the framework and its operation. In the concluding section, the author makes a prediction of the prospect of Appraisal System" $(2001,13)$. After reviewing the application of Appraisal Theory in historical discourse, commercial discourse and so on, Li Zhanzi pointed out some problems in the development of Appraisal Theory. She emphasized that we should "further understand the inter-personality of the Attitude and the importance of the context in Appraisal approach" (2004: 3-4). Hu Zhuanglin introduces "the definition, scope, and classification of evaluation, with particular reference to the functional views, ways of representation of evaluation, such as words, grammar, phonology, metaphor, and multimodality; theories which guide the research of evaluation" $(2009,1)$.

\section{Application of Appraisal Theory}

With the development of Appraisal Theory, a lot of scholars applied it to various discourses, such as in daily conversions, in Media Literature, in academic discussion, in periodicals and in public speeches. In recent years, the application of Appraisal Theory to translation is growing, adding new vi- tality to the field of translation research. The development of appraisal theory in translation research is represented by Jeremy Munday's book Evaluation in Translation: Critical Points of Translator Decision-making, which was published in 2012 and mainly introduced the relationship between appraisal theory and translation. In the book, he did empirical researches on how translators choose their translation strategies from the perspective of Appraisal Theory. His research objects involve many kinds of fields, such as political speech, science and technology translation, literary translation and so on.

In China, a number of scholars make researches on the application of Appraisal Theory. Zhang Meifang thinks "in the translation process, the translator, consciously or unconsciously, often adjusts the original appraisal with his own attitude" (2002: 15) and she "attempts to investigate the causes to the translator's 'unfaithfulness' within the Systemic Functional Linguistic framework" (2002: 15). Zhang Xiangang argues that "Appraisal Theory can provide translation study with an efficient tool in analyzing the attitudinal meaning. In addition, the dialogistic perspective in Appraisal Theory can also shed light on translation study" (2007, 33). Xu Jun "takes the editorial discourse as a case to discuss the validity and feasibility of using Appraisal Theory in business translation" (2011, 88). Liu Shizhu "on the basis of Appraisal Theory, explores the recognition, analysis and expression of attitude, engagement and graduation resources in the process of translating evaluative meanings and constructs a model of translation process" $(2012,28)$. Pei Jihong briefly summarizes the studies on Appraisal Theory at home and abroad and points out that "the application of Evaluation Theory is broad and it can be applied to the fields of discourse analysis, translation and teaching. But there are also some shortcomings that need to be solved" $(2015,92)$. Du Hai believes that "writer's attitudes and meaning potential embedded in texts can be revealed by Appraisal System and resources" and his research is "to help learners understand text from interpersonal meaning so as to better the ability of insight, and cultivate learners' ability of independent analysis" (2016, 173). Li Chengchen and Jiang Guiying "employs 30 Chinese and 30 English forewords of academic monographs as its data and makes a contrastive analysis of these treatises based upon the Attitude of Appraisal System within SFL by using SPSS 22.0, investigating the resource types and realizations of Attitude" $(2017,43)$

\section{Introduction of Attitude System}

According to Martin and White (2008: 33), appraisal is one of three major discourse semantic resources construing interpersonal meaning (alongside involvement and negotiation). It mainly studies how the speaker or author expresses his subjective attitude in language. Appraisal itself is regionalized as three interacting domains - 'attitude', 'engagement' and 'graduation'. Attitude is concerned with our feelings, including emotional reactions, judgments of behaviour and evaluation of things. Engagement deals with sourcing attitudes and the play of voices around opinions in discourse. Graduation attends to grading phenomena whereby feelings are ampli- 
Table 1. Distribution of attitudinal resources

\begin{tabular}{|c|c|c|c|c|c|c|}
\hline \multirow[t]{2}{*}{ Attitudinal resources } & \multicolumn{2}{|c|}{ Li bai's } & \multicolumn{2}{|c|}{ Ezra pound's } & \multicolumn{2}{|c|}{ Xu yuanchong's } \\
\hline & No. & Percentage & No. & $\operatorname{Per}(\%)$ & No. & Percentage \\
\hline Affect & 4 & 30.7 & 4 & 33.3 & 5 & 38.5 \\
\hline Judgment & 5 & 38.5 & 3 & 25.0 & 5 & 38.5 \\
\hline Appreciation & 4 & 30.7 & 5 & 41.7 & 3 & 23.0 \\
\hline Total & 13 & 100 & 12 & 100 & 13 & 100 \\
\hline
\end{tabular}

Table 2. Distribution of the subsystem of attitudinal resources

\begin{tabular}{|c|c|c|c|c|c|c|c|}
\hline \multirow[t]{2}{*}{ Attitudinal system } & \multirow[t]{2}{*}{ Subsystems } & \multicolumn{2}{|c|}{ Li bai's } & \multicolumn{2}{|c|}{ Ezra pound's } & \multicolumn{2}{|c|}{ Xu yuanchong's } \\
\hline & & No. & Percentage & No. & $\operatorname{Per}(\%)$ & No. & Percentage \\
\hline \multirow[t]{3}{*}{ Affect } & Affect as 'quality' & 1 & 25.0 & 2 & 50.0 & 2 & 40.0 \\
\hline & Affect as'process' & 3 & 75.0 & 2 & 50.0 & 3 & 60.0 \\
\hline & Affect as 'comment' & 0 & 0 & 0 & 0 & 0 & 0 \\
\hline \multirow[t]{2}{*}{ Judgment } & Social esteem & 4 & 80.0 & 3 & 100 & 4 & 80.0 \\
\hline & Social sanction & 1 & 20.0 & 0 & 0 & 1 & 20.0 \\
\hline \multirow[t]{3}{*}{ Appreciation } & Reaction & 3 & 75.0 & 3 & 60.0 & 2 & 66.7 \\
\hline & Composition & 1 & 25.0 & 2 & 40.0 & 1 & 33.3 \\
\hline & Valuation & 0 & 0 & 0 & 0 & 0 & 0 \\
\hline
\end{tabular}

Table 3. Distribution of positive/negative attitude and explicit/implicit attitude

\begin{tabular}{|c|c|c|c|c|c|c|}
\hline \multirow[t]{2}{*}{ Polarity/explicitness } & \multicolumn{2}{|c|}{ Li bai's } & \multicolumn{2}{|c|}{ Pound's } & \multicolumn{2}{|c|}{ Xu yuanchong's } \\
\hline & No. & Percentage & No. & $\operatorname{Per}(\%)$ & No. & Percentage \\
\hline Positive & 10 & 76.9 & 10 & 83.3 & 10 & 76.9 \\
\hline Negative & 3 & 23.1 & 2 & 16.7 & 3 & 23.1 \\
\hline Explicit & 9 & 69.2 & 10 & 83.3 & 12 & 92.3 \\
\hline Implicit & 4 & 30.8 & 2 & 16.7 & 1 & 7.7 \\
\hline
\end{tabular}

fied and categories blurred (Martin and White, 2008: 35). The engagement system can be divided into monogloss and heterogloss. The graduation system can be divided into force and focus. Attitude is divided into three regions of feelings, that is, 'affect', 'judgment' and 'appreciation'.

Affect is the center of the three subsystems of attitude. Affect is concerned with registering positive and negative feelings: do we feel happy or sad, confident or anxious, interested or bored? (Martin and White, 2008: 42) Affect system can be divided into affect as 'quality', affect as 'process', affect as 'comment'. Affect as “quality” generally uses quality adjectives or phrases to express emotions. Affect as "process" uses process clauses to express feelings, mainly including mental process and behavioral process. Affect as "comment" uses modal adjunct to comment on the clause process.

Judgment deals with attitudes towards behavior, which we admire or criticize, praise or condemn. (Martin and White, 2008: 42) Judgment can be divided into social esteem and social sanction. "Judgments of esteem have to do with 'normality' (how unusual someone is), 'capacity' (how capable they are) and 'tenacity' (how resolute they are), while judgments of sanction have to do with 'veracity' (how truthful someone is) and 'propriety' (how ethical someone is).” (Martin and White, 2008: 52)
Appreciation involves evaluations of semiotic and natural phenomena according to the ways in which they are valued or not in a given field. (Martin and White, 2008: 43) In general terms appreciation can be divided into our 'reactions' to things (do they catch our attention; do they please us?), their 'composition' (balance and complexity), and their 'value' (how innovative, authentic, timely) (Martin and White, 2008: 43).

The appraisal system mainly evaluates the subjective ideology of the language users through the evaluation vocabulary. Polarity and explicitness are the important features of Attitude. Polarity is the feature to express speaker's or writer's attitude of approval or disapproval. Explicitness deals with the way of evaluation. Polarity can be positive attitude and negative attitude and explicitness can be explicit attitude and implicit attitude. In the next part, the authors will analyze the distribution of the attitudinal resources and the polarity and explicitness in the English versions of the poem.

\section{RESULTS AND DISCUSSION}

\section{Comparative Analysis of Attitudinal Resources}

The Chinese poem has 15 Li Baines, 180 words. Li Bai uses the first person as a businessman's wife to describe her and 
her husband's innocent childhood, their marriage, and her missing her husband after his departure. There is a wealth of attitudinal resources in the Chinese poem and the two English versions; their distribution is shown in the following tables.

Distribution of the attitudinal resources in the original poem and Pound's and Xu Yuanchong's versions shows in the above table. Attitude resources are mainly realized through words, phrases and sentences. There are similarities and differences between the two English versions. As for the similarities, they use some similar words and attitudinal resources in their translation. For example, Pound and $\mathrm{Xu} \mathrm{Yu}-$ anchong translate "差颜” into "being bashful" and "bashful face", which is rather similar.

Compared with the similarities, there are more differences between the two English versions. Table 1 and Table 2 show: In general, there are more attitudinal resources in $\mathrm{Xu}$ Yuanchong's translation version (13) than in Pound's version (12). The affect resources in Xu Yuanchong's version (38.5\%) are more than those in Pound's (33.3\%). Xu Yuanchong $(60.0 \%)$ uses more process affect resources than Pound (50.0\%). For example:

Example 1

Li Bai: 感此伤妾心 $\left(\mathrm{AF}^{1}\right)$, 坐愁红颜老( $\left.\mathrm{AF}\right)$.(Line 13)

Ezra Pound: They hurt me (AF), I grow older (Graduation). (Line 25)

$\mathrm{Xu}$ Yuanchong: This sight would break my heart (AF) and I'm afraid (Line 25)

Sitting alone, my rosy cheeks would fade (AF). (Line 26)

Li Bai in the original poem uses quality affect resources, such as “伤妾心” and “愁...老” to express the heroine's missing her husband and her loneliness when she cannot stay with him, reflecting the heroine's sad feelings by using the process affect. Pound translates “伤妾心” as process affect "They (butterflies) hurt me", which is easy to give people the illusion: The heroine is sad because of the butterflies. Pound translates “愁...老” into “older”, which belongs to graduation resource. His translation is too simple and not able to express the heroine's sigh of her fate. Xu Yuanchong translates them into two process affect resources: "break my heart" and "I'm afraid. fade", which is more specific than Pound's version and fully expresses the heroine's sadness and sorrow.

The judgment resources in $\mathrm{Xu}$ Yuanchong's version (38.5\%) are more than those in Pound's (25.0\%). The biggest difference is that there is no social sanction in Pound's version $(0 \%)$, while $\mathrm{Xu}$ Yuanchong has translated the social sanction resource in the original poem (20.0\%).

Example 2

Li Bai: 常存抱柱信（JU/P/ $\mathrm{Im}^{2}$ ），岂上望夫台. (Line 7)

Ezra Pound: Forever and forever and forever (Graduation) (Line 13)

Why should I climb the look out? (Line 14)

$\mathrm{Xu}$ Yuanchong: Rather than break faith, you declared you'd die $\left(\mathrm{JU} / \mathrm{P} / \mathrm{Ex}^{3}\right)$. (Line 13)

Who know I'd live alone in a tower high? (Line 14)

“抱柱信” is an allusion from the book Zhuangzi, which is written by the main representative of the Taoist school --- Zhuangzi. According to allusion, a man named Weisheng agreed to meet his lover on the bridge, but she didn't show up. The water rose to the bridge, but Weisheng wouldn't leave and finally died holding the bridge pillar. Therefore the allusion is used to describe that one sticks to his or her promises. “抱柱信”, which belongs to social sanction of judgment resources, conveys the heroine's good wishes and the faithful love for her husband. Pound does not translate the allusion, on the contrary, he translates the judgment resource into graduation resource by using three intensifiers "forever", which not only describes the faithful love between the hero and heroine and deepens the impression to the readers, but also creates rhythmic beauty. Xu Yuanchong is more faithful to the original poem. He translates the allusion as "Rather than break faith, you declared you'd die", which also belongs to social sanction, to specifically convey the connotation of the allusion. Xu Yuanchong uses the same appraisal resource as the original poem. Although the two translators employ different appraisal resources, both of them manage to express the strong love between the hero and heroine.

Appreciation resources in $\mathrm{Xu}$ Yuanchong's translation version $(23.0 \%)$ are less than those in Pound's version (41.7\%). For example:

Example 3

Li Bai: 十六君远 $\left(\mathrm{AP}^{4}\right)$ 行 (Line 8)

门前迟 $(\mathrm{AP} / \mathrm{P} / \mathrm{Im})$ 行迹 (Line 10)

Ezra Pound: At sixteen you departed, you went into far (AP) Ku-to-yen (Line 15)

You dragged (AP/P/Ex) your feet when you went out. (Line 19)

$\mathrm{Xu}$ Yuanchong: I was sixteen when you went far away (Line 15)

Your footprints, hidden, can be seen no more (AP/P/Ex). (Line 20)

The meaning of the original poem is that the heroine's husband went far away. The heroine walks slowly in front of the door every day so that small puddles are formed gradally and mosses grow out in these puddles. Pound translates the appreciation resources “远” and “迟” in the original poem into "went into far" and "dragged" to express the heroine's missing and a sense of reluctance to part from her husband who has been gone far away to do business. Xu Yuanchong translates them as "went far away" and "hidden, can be seen no more". Pound's translation, which is more concise and vivid than $\mathrm{Xu}$ Yuanchong's, emphasizes that the young woman is looking forward for her husband's return, highlighting the young woman's missing her husband.

Example 4:

Li Bai: 一一生(Graduation)绿苔(Line 10)

苔深(AP)不能扫 (Line 11)

Ezra Pound: The moss is grown, the different (AP) mosses, (Line 20)

Too deep (AP) to clear them away. (Line 21)

$\mathrm{Xu}$ Yuanchong: Moss can't be swept away: so thick (AP) it grows. (Line 21)

In example 4, “一一生” belongs to graduation resource. Pound adds appreciation resource here. He translates it into an appreciation resource "different mosses", which belongs to composition in appreciation. While $\mathrm{Xu}$ Yuanchong ig- 
nores this sentence and does not translate it. Pound converts the graduation resource into an appreciation resource based on the way of English expression. He does better than $\mathrm{Xu}$ Yuanchong in the translation of this sentence. In the second sentence, Pound and $\mathrm{Xu}$ Yuanchong translates the appreciation resource “深” as “deep” and “thick”, which both have expressed the original poetic mood.

\section{Comparative Analysis of Polarity and Explicitness}

Polarity and explicitness are also important features of attitude. To further analyze the differences of the attitudinal resources in the two English versions, the amount and proportion of the positive/negative attitude and explicit/implicit attitude are listed in Table 3.

As for the positive and negative attitude, the proportion of negative attitude in Xu Yuanchong's version (23.1\%) is more than in Pound's (16.7\%). Xu Yuanchong's translation is more flexible. He converts positive attitude in the Chinese poem into negative attitude. For example, in the example 3, “迟” belongs to positive attitude. Pound translates it as positive attitude "dragged", while Xu Yuanchong translates it as negative attitude "hidden, can be seen no more". "Dragged" is more concise and vivid than the phrase "hidden, can be seen no more". And Xu Yuanchong also converts negative attitude into positive attitude. For example,

Example 5:

Li Bai: 两小无嫌猜(AF/P/Ex) (Line 3)

愿同(AF/P/Im) 尘与灰(Line 6)

Ezra Pound: Two small people, without dislike (AF/N5/ Ex) or suspicion (AF/N/Ex) (Line 6)

I desired (AF/P/Im) my dust to be mingled with yours. (Line 12)

$\mathrm{Xu}$ Yuanchong: Carefree (AF/P/Ex) and innocent $(\mathrm{AF} / \mathrm{P} /$ Ex), we children twain (Line 6)

To mix my dust with yours were my dear vows (AF/P/ Ex). (Line 12)

Positive resource “无嫌猜” is translated into two negative resources "dislike" and "suspicion" by Pound, while Xu Yuanchong translates it into two positive resources "carefree" and "innocent". The two versions both have increased the affect resources, which reflect a common feature of the translation of ancient poetry, that is, to meet the needs of target readers, translators often choose to add some attitudinal resources to help the readers understand the original poem better. The Chinese phrase “无嫌猜” means that the heroine and her husband grow up together and happily. It does not emphasis that they dislike or doubt each other. Comparatively speaking, Xu Yuanchong has expressed the happiness and innocent emotions between the couple. His translation is better than Pound's on this sentence.

As for the distribution of the explicitness of the poems shown in Table 3, Xu Yuanchong and Pound both add explicit attitude during their translation. They both convert some implicit attitude resources into explicit attitude resources. For example, in the example 3, the poet, Li Bai in the original poem uses implicit attitude “迟”. Pound and Xu Yuanchong both translate it into explicit attitude "dragged" and "hidden, can be seen no more". The meaning of “迟” is dif- ficult to understand. Their translation expresses the meaning of the original poem explicitly, which is easy for the readers to understand the poem. However, the differences between the two versions are obvious. There are more explicit attitude resources in $\mathrm{Xu}$ Yuanchong's $(92.3 \%)$ version than in Pound's (83.3\%). Xu Yuanchong converts implicit attitude to explicit attitude. For example, in the example 5, Pound translate implicit resources “愿同” as “I desired”, Xu Yuanchong translates it as explicit attitude "my dear vows". Pound's version is consistent with the original poem. But Xu Yuanchong translates it as an explicit resource, which more explicitly expresses the heroine's thought and desire. Another example, in the example 2, “抱柱信” is from an allusion which is an implicit expression. Pound translates the judgment resource into a graduation resource. Xu Yuanchong translates it as an explicit resource "Rather than break faith, you declared you'd die", which combines the content of the poem with the meaning of the allusion and conveys the original meaning of the story. Each version has its own characteristics and both have expressed the meaning of the original poem.

In summary, the distribution of attitudinal resources in the two English versions is as follows: $\mathrm{Xu}$ Yuanchong employs more affect and judgement resources $(38.5 \%, 38.5 \%)$ than Pound do $(33.3 \%, 25.0 \%)$. While Pound uses more appreciation resources (41.7\%) than $\mathrm{Xu}$ Yuanchong do (23.0\%). Xu Yuanchong uses more affect resources to intensify the emotion in order to make the readers get a better and full understanding of the original poems. Pound simplifies the original poem and ignores the translation of some allusions, so that the poem is easily understandable and concise to the foreign readers. Pound employs more appreciation resources to express the poet's feelings for natural phenomenon. As for positive/negative attitude and explicit/implicit, the distribution is roughly equal and both of the two translation versions make conversions. $\mathrm{Xu}$ Yuanchong's translation is more flexible than Pound's, especially in the translation of implicit attitude resources. He converts many implicit attitude resources into explicit attitude resources to make the poem more understandable for readers.

\section{REASONS FOR THE DIFFERENCES}

After the detailed analysis of the attitudinal resources and the positive/negative, explicit/implicit attitudes used in Changgan Xing and its English versions, the differences of attitudinal resources used in the two translation versions are clearly pointed out. According to Zhang Meifang, "if translators come across difficulties during the translation, such as language barriers, background of culture, incapability of translation or lack of materials, the translation may deviate from the original text. And these deviations would further trigger the deviation of the translation of appraisal resources" (2005: 27). The following part stresses on the causes of their differences, including the cultural background of the translators and their translation theories or strategies.

\section{Cultural Background}

The comprehension of the original poem is the first and the most important step during translation. So the cultural back- 
ground of translators is the first factor to consider. Pound, American poet and literary critic, is a representative of the imagist. He is one of the leading figures of postsymbolism. From the study of the Chinese classical poetry and the Japanese haiku, he put forward the theory of "poetic imagery", and made great contributions to the study of Eastern and Western poetry. Pound does not understand Chinese. The Chinese classical poetry can be translated because he got Earnest Fenollosa's private manuscript. Pound chooses 19 Chinese classical poems and translates them into English, including Li Bai's Changgan Xing. Pound's translation of Li Bai's works has already been the second interpretation, which can cause misunderstanding to the poem. Xu Yuanchong is an expert in translation of the classical poetry. He has published numbers of works of translation and translation theories. He has introduced many Chinese classical works to the foreign countries and has been acknowledged as an outstanding translator in the translation of Chinese classical poems. Xu Yuanchong himself is a Chinese and a proficient in Chinese classical poetry. Therefore, he has a better understanding of the original poem. The implication of the allusions has been accurately translated. His translation version has expressed more details of the original poem. For example, in the example 2, Xu Yuanchong has fully translated the meaning of the allusion “抱柱信”.

\section{Translation Theories}

Translation theories or methods that translators employed have a great influence on the translation of attitudinal resources. In this paper, Xu Yuanchong and Pound selected two different translation theories and had different opinions on poetic translation during their translation. Pound is a representative of the imagist movement and he is very fond of imagist poetry which especially emphasizes the hazy beauty. Therefore, the interpretation of concrete words is not taken very seriously. In order to pursue the creation of hazy beauty, Pound's interpretation of Li Bai's poetry damages the poetic mood and rhythmic beauty of the original poem. And Pound himself also explained that he was eager to pursue the image of the poem and did not blindly interpret the meaning of poem but to grasp more details and compress the author's thoughts and feelings. Xu Yuanchong applied $\mathrm{Lu}$ Xun's "three beauties" to translation, and it became "Three Beauties Principle" on poetry translation, that is, the beauty in sense, sound and form. He has practiced his theory of Three Beauties Principle, which has a great significance to the practice of poetry translation, and may be assumed as a milestone in the field of theory for poetry translation. In Xu Yuanchong's opinion, "to preserve the beauty in sense we may use the method of 'paraphrase' (free or liberal translation); to preserve the beauty in sound, we may use the method of 'imitation' (or adaptation); to preserve the beauty in form, we may use the method of 'metaphrase' (or literal translation)" (2006: 131).

Their translation approaches are different. Therefore, their interpretation of the attitudinal resources in Changgan Xing is also different from each other. Zhang Meifang has said that "Chinese people like to use adjective words to de- scribe things, especially scenery in their articles. And so in the translation, Chinese translators usually use the adjective lexis to interpret the abstract meanings" (2002: 17) However, "western translators adhere to the ancient Greek culture and pay more attention to their logical meanings, and by the constraint of its highly formalized language, so translators intend to use lexis which is concise and easy to understand in their translations" (Qian Hong, 2007: 63). As a result, Xu Yuanchong's translation has more attitudinal resources than Pound's version.

\section{Other Possible Reasons}

Meanwhile, source language is also an important factor for the different translations in the translation of poems. Changgan Xing was written in ancient Chinese. Different from modern Chinese, ancient Chinese is hard to understand even for native Chinese not to mention that Pound does not understand Chinese at all. There are other possible reasons for their differences; however, due to the limitation of space, this paper will not analyze them in detail.

\section{CONCLUSION}

The paper studies the quantity, types and distribution of the three subsystems of affect resources in Changgan Xing. And it also analyzes the distribution of polarity and explicitness of the attitudinal resources. It shows the applicability of the appraisal theory in the analysis of poem translation, and extends the application scope of the appraisal theory. The study finds that: First of all, both of the two translated poems employ abundant attitudinal resources. All the three types of attitudinal resources can be found in the original poem and the two translation versions. Secondly, in order to eliminate the differences caused by cultural background, Xu Yuanchong's version increases the affect and judgment resources to help readers understand the meaning of the original poem, but the language lacks of rhythm and the expression is a little complicated. Affect and judgment resources in Pound's version are reduced in order to retain the beautiful rhythm and concise language. However, the allusions and affect and judgment resources in the original poem are not fully translated and the appraisal meaning is not totally conveyed. Thirdly, the proportion of positive/negative and explicit/implicit attitude resources in the English versions is roughly equal. But $\mathrm{Xu}$ Yuanchong uses more explicit expressions than Pound, which shows that Xu Yuanchong's version conveys more details in the poem than Pound's version. By comparing the two translation versions, the authors have found that both of them make some adjustments and adopt different translation skills in the translation of attitudinal resources. Readers and Enlish learners cannot arbitrarily think which translation version is relatively better than another. Finally, translators' cultural background and different translation approaches are the main reasons leading to the deviation from the original poem and the differences between the two translation versions.

We believe that in the translation of poem, due to the constraints of the characteristics of different languages and the translators' cultural background, it is inevitable that the 
choice of appraisal types and the frequency and amount of appraisal resources are all made some changes. The translators should take full account of the characteristics of the two languages and the original poem's cultural background in the process of translation. It is necessary for the translators to deal with the appraisal resources of the original poems more rationally, and at the same time pay more attention to the conveyance of the poetic mood, so that the appraisal meaning in the original poem can be realized and the original poetic mood and cultural characteristics can be retained.

There are some limitations and suggestions for further study. Firstly, this study only analyzes one poem, the corpus is inadequate. The further study can take more poems into consideration. Secondly, due to the limited space, the paper mainly studies attitudinal resources and its subsystems in the original poem and the translation versions. The engagement system and graduation system in the poems need to be further explored.

\section{NOTES}

1. AF: abbreviation of "affect".

2. JU/P/Im: "JU" is the abbreviation of "judgment". "P" is the abbreviation of "positive". "Im" is the abbreviation of "implicit".

3. Ex: abbreviation of "explicit".

4. AP: abbreviation of "appreciation".

5. N: abbreviation of "negative".

\section{REFERENCES}

Du, H. (2016) Research on College Foreign Language Teaching-From the perspective of Appraisal Theory. Heilongjiang Researches on Higher Education 0(3), 171-173. http://dx.doi.org/10.3969/j.issn.1003-2614.2016.03.047

Hu, Z. (2009) Approaches of Evaluation in Text. Foreign Language Education 30(1), 1-6. http://dx.doi. org/10.16362/j.cnki.cn61-1023/h.2009.01.006

Li, C, \& Jiang, G. (2017) A Comparative Study of forewords between Chinese and English Academic Monographs from the Perspective of Attitude System in Appraisal Theory. Foreign Language Education 38(5), 43-48. http:// dx.doi.org/10.16362/j.cnki.cn61-1023/h.2017.05.009
Li, Z. (2004) Appraisal Theory:Applications and Probems in Discourse Analysis. Foreign Languages Research 0(5), 1-6. http://dx.doi.org/10.3969/j.issn.1005-7242.2004.05.001

Liu, S. (2012) A Model of Translation Process Within Appraisal Theory. Shandong Foreign Language Teaching Journal 0(4), 24-28. http://dx.doi.org/10.3969/j. issn.1002-2643.2012.04.005

Martin, J. R. (2008) The language of evaluation: Appraisal in English. Beijing: Foreign Language Teaching and Research Press.

Pei, J. (2015) Literature Review on the Appraisal Theory. Science and Technology of West China 0(1), 90, 92.http:// dx.doi.org/10.3969/j.issn.1671-6369.2015.01.40

Pound, E. (1915) Cathay: Translations by Ezra Pound. For the Most Part from the Chinese of Rihaku, from the Notes of the Late Ernest Fenollosa, and the Decipherings of the Professors Mori and Ariga (pp. 11-12). London: Elkin Mathews.

Qian, H. (2007) Investigating Unfaithful Translations via the Appraisal Theory- A Case Study on Perfume Ads Translation. Journal of Foreign Languages 0(6), 57-63.

Wang, Z. (2001) Apprasal Systems and Their Operation: A New Development in the Systemic Functional Linguistics. Journal of Foreign Languages 0(6), 13-20.

http://dx.doi.org/10.3969/j.issn.1004-5139.2001.06.002

$\mathrm{Xu}$, J. (2011) Study on Business Translation from the Perspective of Appraisal Theory. Journal of PLA University of Foreign Languages 34(6), 88-91, 109.

Xu, Y. (2006) The Art of Translation. Beijing: Wuhu Communication Publishing Press.

Xu, Y. (2007) Selected Poems of Li Bai (pp. 22-25). Changsha: Hunan People's Publishing Press.

Zhang, M. (2002) Appraisal and the Translator's Attitude. Foreign Languages and Their Teaching 0(7), 15-18. http://dx.doi.org/10.3969/j.issn.1004-6038.2002.07.004

Zhang, M. (2005) Functional Approaches to Translation Studies. Shanghai: Shanghai Foreign Language Education Press.

Zhang, X. (2007) Implications of Appraisal Theory for Text Translation. Foreign Language Education 28(6), 33-36. http://dx.doi.org/10.3969/j.issn.1000-5544.2007.06.008 


\section{APPENDIX}

长干行

李白

妾发初覆额, 折花门前剧。

郎骑竹马来, 绕床弄青梅。

同居长干里, 两小无嫌猜。

十四为君妇, 羞颜未尝开。

低头向暗壁, 千唤不一回。

十五始展眉, 愿同尘与灰。

常存抱柱信, 岂上望夫台。

十六君远行, 翟塘滟滪堆。

五月不可触, 猿鸣天上哀。

门前迟行迹, 一一生绿苔。

苔深不能扫, 落叶秋风早。

八月蝴蝶来, 双飞西园草。

感此伤妾心, 坐愁红颜老。

早晚下三巴，预将书报家。

相迎不道远, 直至长风沙。

The River Merchant's Wife: a Letter

Ezra Pound

While my hair was still cut straight across my forehead

I played about the front gate, pulling flowers.

You came by on bamboo stilts, playing horse,

You walked about my seat, playing with blue plums.

And we went on living in the village of Chokan:

Two small people, without dislike or suspicion.

At fourteen I married My Lord you.

I never laughed, being bashful.

Lowering my head, I looked at the wall.

Called to, a thousand times, I never looked back.

At fifteen I stopped scowling,

I desired my dust to be mingled with yours

Forever and forever and forever.

Why should I climb the look out?

At sixteen you departed,

You went into far Ku-to-en, by the river of swirling eddies,

And you have been gone five months.

The monkeys make sorrowful noise overhead.

You dragged your feet when you went out.

By the gate now, the moss is grown, the different mosses,
Too deep to clear them away!

The leaves fall early this autumn, in wind.

The paired butterflies are already yellow with August

Over the grass in the West garden;

They hurt me. I grow older

If you are coming down through the narrows of the river Kiang,

Please let me know beforehand,

And I will come out to meet you

As far as Cho-fu-Sa.

Ballads of a Merchant's wife

$\mathrm{Xu}$ Yuanchong

My forehead covered by my hair cut straight,

I played with flowers pluck'd before the gate.

On a hobbyhorse you came upon the scene,

Around the well we played with mumes still green.

We lived close neighbors on riverside lane.

Carefree and innocent, we children twain.

I was fourteen when I became your bride,

I'd often turn my bashful face aside.

Hanging my head, I'd look towards the wall,

A thought times I'd not answer your call.

I was fifteen when I composed my brows,

To mix my dust with yours were my dear vows.

Rather than break faith, you declared you'd die.

Who know I'd live alone in a tower high?

I was sixteen when you went far away,

Passing Three Gorges studded with rocks gray,

Where ships were wrecked when spring flood ran high,

Where gibbons' wails seemed coming from the sky.

Green moss now overgrows before our door,

Your footprints, hidden, can be seen no more.

Moss can't be swept away: so thick it grows,

And leaves fall early when the west wind blows,

The yellow butterflies in autumn pass

Two by two o'er our western garden grass.

This sight would break my heart and I'm afraid,

Sitting alone, my rosy cheeks would fade.

Sooner or later, you'll leave the western land.

Do not forget to let me know beforehand.

I'll walk to meet you and not call it far

To go to Long Wind Sands or where you are. 